\title{
Assessment for Hypertension Risk Score in Pune Urban Population
}

\author{
Sudhir Gavali ${ }^{1}$, Deepak Tambe ${ }^{2}$, Shishir Joshi ${ }^{3}$, A Pranita ${ }^{2}$, J.S. Kharche1, Gayatri Godbole ${ }^{2}$, \\ Anuradha Joshi ${ }^{4}$ \\ ${ }^{1}$ Associate Professor, ${ }^{2}$ Assistant Professor, Department of Physiology, Bharati Vidyapeeth (Deemed to be \\ University) Medical College, Pune, ${ }^{3}$ Consulting Physician, Sanjivani Health Care Center, Pune, ${ }^{4}$ Professor \& \\ Head, Department of Physiology, Bharati Vidyapeeth (Deemed to be University) Medical College, Pune
}

\begin{abstract}
Introduction: The World health statistics 2012 report highlight on the growing problem of the noncommunicable diseases burden due to urbanisation and change in the life styles. According to the WHO report, one in three adults worldwide, has hypertension a condition that causes around half of all deaths from stroke and heart disease.In this study, we are using the common modifiable risk factors like obesity and exercise status to evaluate risk of hypertension in later life. So the present study is planned to calculate the risk score for the development of hypertension. Material \& Method: It was a cross sectional study. Study was conducted on about 521 individuals between the age group of 18-50 yrs in Pune urban population. Risk factors like obesity,physical activity .family history and depression were used to assess score Results: In our study total 521 participants were included out of which $27 \%, 58 \%$ and $15 \%$ have mild, moderate and high risk of developing hypertension respectively in future. Conclusion: The study concludes that majority of urban Pune population have moderate risk of hypertension. This highlights need of preventable measures like counselling sessions, regular follow up, life style modification in form of increased physical activity and healthy diet.
\end{abstract}

Kaywords : Hypertension, Risk score, Urban population

\section{Introduction}

The World health statistics 2012 report highlight on the growing problem of the non-communicable diseases burden due to urbanization and change in the life styles.

According to the WHO report, one in three adults worldwide, has hypertension a condition that causes around half of all deaths from stroke and heart disease. ${ }^{1}$

Most of these people remain undiagnosed, although many of these cases could be treated with low-cost medications, which would significantly reduce the risk of death and disability from heart disease and stroke.

\section{Corresponding Author:}

Dr. Deepak Tambe,

Address: 805, Neelam Apartments, Shree Mahalaxmi

Nagar, Chaitraban, Bibwewadi, Pune - 411037.

Phone no.:8796974215.

Email: sudhirgavali0069@gmail.com
Also left untreated can lead to cardiovascular disease, blindness and kidney failure. ${ }^{2}$

Globally cardiovascular disease accounts for approximately 17 million deaths a year, nearly one third of the total .Of these, complications of hypertension account for 9.4 million deaths worldwide every year. Hypertension is responsible for at least $45 \%$ of deaths due to heart disease and $51 \%$ of deaths due to stroke ${ }^{3}$

In an analysis of worldwide data for the global burden of HTN, $20.6 \%$ of Indian men and $20.9 \%$ of Indian women were suffering from HTN in 2005. The rates for HTN in percentage are projected to go up to $22.9 \%$ and $23.6 \%$ for Indian men and women, respectively by 2025 . Recent studies from India have shown the prevalence of HTN to be $25 \%$ in urban and $10 \%$ in rural people in India. According to the WHO 2008 estimates, the prevalence of raised BP in Indians was $32.5 \%$ ( $33.2 \%$ in men and $31.7 \%$ in women). However, only about $25.6 \%$ of treated patients had their 
BP under control, in a multicenter study from India on awareness, treatment and adequacy of control of HTN. ${ }^{5}$

Previously a disease of the middle-aged and elderly hypertension has recently escalated in all age groups and is now being identified in younger and younger age groups, including adolescents and children, especially in high-risk populations adds to the total cardiovascular disease burden and threatens to slow progress toward the goals for heart disease and stroke mortality through the remainder of the decade. ${ }^{5,6}$ This underscores the need for mass awareness and screening programmes to detect HTN at an early stage.

Physical inactivity and overweight or obesity with genetic component and stress are the important risk factors for the development of hypertension.

In this study, we are using the common modifiable risk factors like obesity and exercise status to evaluate risk of hypertension in later life. So the present study is planned to calculate the risk score for the development of hypertension.

\section{Material \& Method}

It was a cross sectional study. Study was conducted on about 521 individuals between the age group of 18-50 yrs in Pune urban population.

Nature of the study was explained to all the subjects $\&$ written consent was taken. All subjects was assessed for risk score as per the Proforma using standard techniques. The waist circumference was taken at the midpoint between the iliac crest and the lower border of the ribs after a normal expiration. Systolic and diastolic blood pressure (BP) was be recorded in the right arm in supine position by using a mercury sphygmomanometer after 5 min rest. Two readings of SBP and DBP were recorded and the mean of each was used.

Assessment of physical activity was done according to Global Recommendations on Physical Activity for Health, WHO $2010{ }^{6}$ An individual is defined as physically active if he/she is performing at least 150 minutes of moderate-intensity aerobic physical activity throughout the week such as walking $30 \mathrm{~min} /$ day for 5 days or doing at least 75 minutes of vigorous-intensity aerobic physical activity such as football and netball, as well as activities such as dancing, running and swimming laps throughout the week or an equivalent combination of moderate- and vigorous-intensity activity.
An individual is defined as physically less active if he/she is performing less than 150 minutes of moderateintensity aerobic physical activity throughout the week such as walking less than $30 \mathrm{~min} /$ day for \& not for maximum 5 days / week or doing at less than 75 minutes of vigorous-intensity aerobic physical activity such as football and netball, as well as activities such as dancing , running and swimming laps throughout the week or an equivalent combination of moderate- and vigorousintensity activity.

An individual is defined as physically inactive if he/ she is performing only activities of daily living.

Depression is common among persons with hypertension. Unfortunately the diagnosis of depression is often missed by health care professionals. Using a short questionnaire as the WHO-5 can help to monitor emotional well-being. For assessment of stress or psychological well being a simple screening tool i.e WHO -5 well being index was used.

The WHO-5 Well-being Index ${ }^{7}$ is a short, selfadministered questionnaire covering 5 positively worded items, related to positive mood (good spirits, relaxation), vitality (being active and waking up fresh and rested), and general interests (being interested in things). It has shown to be a reliable measure of emotional functioning and a good screener for depression. Administering the WHO-5 Well-being Index takes 2-3 minutes and can be integrated in clinical routine, both in primary and secondary care.

Each of the five items is rated on a 6-point Likert scale from 0 (= not present) to 5 (= constantly present). A score below 13 indicates poor wellbeing. If the raw score is below 13 or if the patient has answered 0 to 1 to any of the five items it is an indication for further assessment to confirm depression.

The levels of blood pressure were taken as per the Indian guideline of blood pressure for hypertension. ${ }^{8}$. We score each of the factors in multiples of 10 for easy counting. Statistical analysis was done by nonparametric test using computerized 'SPSS' software version 10. 
Table 1: Risk score for Hypertension

\begin{tabular}{|c|c|}
\hline Risk factors & HTN Score \\
\hline \multicolumn{2}{|l|}{ Age } \\
\hline$<35$ & 0 \\
\hline $35-49$ & 20 \\
\hline$>50$ & 30 \\
\hline \multicolumn{2}{|l|}{ Waist Circumference (cm) } \\
\hline \multicolumn{2}{|l|}{ Female / Male } \\
\hline$<80 /<90$ & 0 \\
\hline $80-89 / 90-99$ & 10 \\
\hline$>90 />100$ & 20 \\
\hline \multicolumn{2}{|l|}{ Physical activity } \\
\hline Physically active & 0 \\
\hline Physically less active & 10 \\
\hline Physically inactive & 20 \\
\hline \multicolumn{2}{|l|}{ WHO - 5 Well being score } \\
\hline$>13$ & 0 \\
\hline$<13 / 0$ or 1 & 10 \\
\hline \multicolumn{2}{|l|}{ Family history } \\
\hline No family history & 0 \\
\hline Either parent (Mother /Father) & 10 \\
\hline Both parent & 20 \\
\hline \multicolumn{2}{|l|}{ Systolic BP } \\
\hline$<130$ & 0 \\
\hline $130-139$ & 10 \\
\hline \multicolumn{2}{|l|}{ Diastolic BP } \\
\hline$<85$ & 0 \\
\hline $85-89$ & 10 \\
\hline \multicolumn{2}{|l|}{ Total Score } \\
\hline Max score & 120 \\
\hline Mild risk & $<50$ \\
\hline Moderate risk & $50-70$ \\
\hline High risk & $>80$ \\
\hline
\end{tabular}

\section{Result}

Table 2: Hypertension Score

\begin{tabular}{|l|l|l|l|}
\hline \multicolumn{2}{|l|}{ Hypertension score } & $\%$ \\
\hline Mild risk & $<50$ & 141 & 27 \\
\hline Moderate risk & $50-70$ & 303 & 58 \\
\hline High risk & $>80$ & 77 & 15 \\
\hline Total & 521 & 100 \\
\hline
\end{tabular}

In our study total 521 participants were included out of which $27 \%, 58 \%$ and $15 \%$ have mild, moderate and high risk of developing hypertension respectively in future.

\section{Discussion}

It was a cross sectional study .Study was conducted on about 521 individuals between the age group of 1850 yrs in Pune urban population. In our study total 521 participants were included out of which $27 \%, 58 \%$ and $15 \%$ have mild, moderate and high risk of developing hypertension respectively in future.

As per the risk score maximum number of participants i.e $58 \%$ (303) were in the moderate risk and 77 i.e. $(15 \%)$ were at high risk may need to take early interventions with drug treatment after detailed investigations. The 141 i.e. $27 \%$ were in the mild risk may need to take precautions regarding weight loss or physical activity stress management so that they should not progress for high risk.

In various studies ${ }^{9,10}$ presence of cardiometabolic risk factors (such as central obesity and high BMI) may have been the contributing factors for high prevalence of HTN in urban and rural parts of India. Increase in HTN with advancing age was shown by various studies. It was observed that sedentary lifestyle and central obesity also increases risk for hypertension.

The differences in HTN prevalence between urban and rural areas noted in our study could be explained by the differences in socioeconomic conditions, risk factors, and quality of healthcare services provided. Lifestyle changes (harmful dietary practices and sedentary habits) occurring because of rapid urbanization and economic progress in urban areas have also contributed to the growing epidemic of HTN in urban areas of India. 
Prevalence of Physical Inactivity of $50.2 \%$. Overall prevalence of Hypertension was $65.1 \%$. There was a linear positive correlation between Age with Diastolic Blood Pressure and Systolic Blood Pressure. ${ }^{11}$

In one of the study they found positive correlation between depression and hypertension. The underlying causes of depression need to be addressed and community programs need to be initiated to raise awareness regarding long-term complications of untreated depression ${ }^{12}$

Thus, if hypertension and it's related complications are detected at an early stage it will help to reduce morbidity and mortality related to hypertension.

\section{Conclusion}

The study concludes that majority of urban Pune population have moderate risk of hypertension. This highlights need of preventable measures like counselling sessions, regular follow up, life style modification in form of increased physical activity and healthy diet.

Ethical Clearance was taken from institutional ethical committee.

Source of Funding Bharati Vidyapeeth Deemed to be University

\section{Conflict of Interest - Nil}

\section{References}

1. Global health risks: mortality and burden of disease attributable to selected major risks. Geneva, World Health Organization, 2009 http:// www. who. int/ healthinfo/global_burden_disease/ Global Health Risks_report_full.pdf).

2. A global brief on hypertension Silent killer, global public health crisis April 2013 .WHO reference number: WHO/DCO/WHD/2013.2

3. Global Recommendations on Physical Activity for Health, WHO 2010 . http://www.who.int/ dietphysicalactivity/factsheet_recommendations/ en/index.html

4. WHO(Five) Well being index. 1998 Version Psychiatric Research Unit WHO Collaborat ing Centre in Mental Health
5. Indian Guidelines Management of Hypertension 2001. Hypertension India 2001; 15 (2): 1-34.

6. Gupta R, Pandey RM, Misra A, Agrawal A, Misra P, Dey S, et al. High prevalence and low awareness, treatment and control of hypertension in Asian Indian women. J Hum Hypertens 2012; 26:585593

7. Meshram II, Arlappa N, Balkrishna N, Rao KM, Laxmaiah A, Brahmam GN. Prevalence of hypertension, its correlates and awareness among adult tribal population of Kerala state, India. $J$ Postgrad Med 2012; 58:255-261 [PubMed] [Google Scholar]

8. Joshi SR, Saboo B, Vadivale M, Dani SI, Mithal A, Kaul U, et al. SITE Investigators Prevalence of diagnosed and undiagnosed diabetes and hypertension in India: results from the Screening India's Twin Epidemic (SITE) study. Diabetes Technol Ther 2012; 14:8-15 [PubMed] [Google Scholar]

9. Hypertension and its risk factors in tea garden workers of Assam. Hazarika NC, Biswas D, Narain K, Kalita HC, Mahanta J Natl Med J India. 2002 Mar-Apr; 15(2):63-8

10. Kinra S, Bowen LJ, Lyngdoh T, Prabhakaran D, Reddy KS, Ramakrishnan L, Gupta R, Bharathi AV, Vaz M, Kurpad AV, Smith GD, Ben-Shlomo Y, Ebrahim Socio demographic patterning of noncommunicable disease risk factors in rural India: a cross sectional study S BMJ. 2010 Sep 27; 341():c4974.

11. Physical Inactivity and Its Association with Hypertension in Adult Female Population of Srinagar, India: a Community Based CrossSectional Study Abdul Rouf1, Mahbooba Rasool2, Mohammad Salim Khan3, Mohd Saleem Sheikh2 National Journal of Community Medicine. Volume 9( 9) , 2018: 693-697

12. Samar Mahmood, Syeda Z Hassan, Muqadus Tabraze, Mohammad O Khan, Iqra Javed, Ameer Ahmed, et al . Prevalence and Predictors of Depression Amongst hypertensive Individuals in Karachi, Pakistan. Cureus. 2017 Jun; 9(6): e1397. 